\title{
TO STUDY THE SIGNIFICANCE OF HRCT OVER CHEST X- RAY IN THE DIAGNOSIS OF INTERSTITIAL LUNG DISEASES
}

\author{
Manoj Kumar Agrawal' ${ }^{1}$ Amit Kumar², Rajesh Agrawal ${ }^{3}$, Rishi Rana ${ }^{4}$ \\ ${ }^{1}$ Associate Professor, Department of TB and CD, Varun Arjun Medical College, Banthara, Uttar Pradesh, India. \\ ${ }^{2}$ Associate Professor, Department of TB and CD, RMCH, Bareilly, Uttar Pradesh, India. \\ 3 Professor, Department of TB and CD, RMCH, Bareilly, Uttar Pradesh, India. \\ 4Junior Resident, Department of TB and CD, RMCH, Bareilly, Uttar Pradesh, India.
}

ABSTRACT
BACKGROUND
Interstitial lung disease (ILD) is a heterogeneous group of diffuse parenchymal lung diseases, characterized by restrictive
physiology, impaired gas exchange, pulmonary inflammation and fibrosis. Chest radiograph (CXR) may be normal during early in
the course of the disease and shows few abnormalities hence unable to identify the specific aetiology of ILD. HRCT (High resolution
computed tomography) is the most accurate non-invasive, high spatial resolution descriptive imaging modality for evaluation of
lung parenchyma. It assesses the presence of disease in lung, type of disease, changes of active lung disease, biopsy site localization,
change in disease activity following treatment, characterization of interstitial lung disease (ILD) in appropriate clinical setting.

\section{MATERIALS AND METHODS}

The descriptive study was conducted on 40 patients having clinical suspicion of ILD in the Department of Tuberculosis and Chest Diseases, Varun Arjun Medical College and Hospital, Banthra \& Department of Pulmonary Medicine, Rohilkhand Medical College and Hospital, Bareilly, during the period of January 2018 to August 2018.

\section{RESULTS}

In this study, the age of the patients ranged from 30 to 74 years. There were $65 \%$ male patients and $35 \%$ female patients. The most common presenting clinical feature was exertional dyspnoea present in $65 \%$ of patients followed by a cough which was present in $56 \%$ of cases. The spectrum of diseases included in the study was: Idiopathic pulmonary fibrosis (25\%), hypersensitivity pneumonitis (17.5\%), sarcoidosis (15\%), rheumatoid arthritis (10\%), silicosis (10\%), LAM (7.5\%), allergic bronchopulmonary aspergillosis (5\%) and lymphangitis carcinomatosis (5\%), COP (5\%).

\section{CONCLUSION}

HRCT of the lung in cases of the suspected interstitial lung diseases forms an invaluable tool for accurate and early identification and in conjunction with the clinical findings can obviate the need of lung biopsy in diagnosis of ILD's.

\section{KEY WORDS}

High Resolution Computed Tomography, ILD.

HOW TO CITE THIS ARTICLE: Agrawal MK, Kumar A, Agrawal R, et al. To study the significance of HRCT over chest x- ray in the diagnosis of interstitial lung diseases. J. Evolution Med. Dent. Sci. 2019;8(02):94-98, DOI: 10.14260/jemds/2019/21

\section{BACKGROUND}

Interstitial lung disease (ILD) is a heterogeneous group of diffuse parenchymal lung diseases, characterize by restrictive physiology, impaired gas exchange, pulmonary inflammation and fibrosis.1,2 In most cases the pathology of ILD lies in the pulmonary interstitium which consist of connective tissue space between the alveolar epithelial cells and the adjacent capillary endothelial cells. Extensive work up is needed for the diagnosis of ILD. ${ }^{3}$ Although the majority of these disorders also involve the air spaces, the predominant abnormality is usually thickening of the interstitium which may be due to the accumulation of fluid, cells, or fibrous tissue. 4

'Financial or Other Competing Interest': None.

Submission 19-11-2018, Peer Review 01-01-2019,

Acceptance 07-01-2019, Published 14-01-2019.

Corresponding Author:

Dr. Amit Kumar,

Flat No. 16, Associate Professor,

Department of TB and CD,

RMCH, Campus, Bareilly,

Uttar Pradesh, India.

E-mail: dr_amitkushwaha@rediffmail.com

DOI: $10.14260 /$ jemds $/ 2019 / 21$

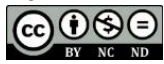

Over 100 distinct entities of ILD are recognized, idiopathic pulmonary fibrosis, sarcoidosis and connective tissue disease related ILD account for most of ILD. The prevalence of the IPF is around 54 per 100000 adults using broad case definition and 17 per 100000 using narrow case definition. Although ILDs are more commonly seen in adults, some forms such as hypersensitivity pneumonitis and idiopathic interstitial pneumonias are encountered in children.

The chest radiograph remains part of the initial assessment of ILD, but the radiographic pattern is often nonspecific, observer variation is considerable and may be normal during early course of the disease and shows few abnormalities hence unable to identify the specific aetiology of ILD. 5,6,7 Pulmonary function testing (PFT) cannot diagnose a specific ILD or distinguish between active lung inflammations versus fibrosis. ${ }^{8}$ HRCT (High resolution computed tomography) is the most accurate non-invasive, high spatial resolution descriptive sectional imaging modality for evaluation of lung parenchyma. It assess the presence of disease in lung, type of disease, changes of active lung disease, biopsy site localization, change in disease activity following treatment, characterization of interstitial lung disease (ILD) in appropriate clinical setting. It is more 
sensitive than the plain radiograph in identifying ILD (sensitivity greater than 90\%) and the image pattern of parenchymal abnormalities on HRCT often suggests a particular set of diagnostic possibilities. ${ }^{9}$

\section{Objectives of the Study}

1. To correlate the findings of conventional chest radiography and HRCT in interstitial lung diseases.

2. To evaluate ILD in symptomatic patients with normal or equivocal chest radiograph findings.

3. To study the different radiographic patterns associated with Interstitial Lung Disease in both conventional chest radiography and HRCT.

\section{MATERIALS AND METHODS}

The descriptive study was conducted on 40 patients having clinical suspicion of ILD in the Department of Tuberculosis and Chest Diseases, Varun Arjun Medical College and Hospital, Banthra \& Department of Pulmonary Medicine, Rohilkhand Medical College and Hospital, Bareilly, during the period of January 2018 to August 2018.

\section{Study Design}

It was a descriptive study. Convenient sampling technique, taking all patients during study period was used.

\section{Inclusion Criteria}

1. Patients suspected of having interstitial lung diseases suspected on chest radiographs.

2. Patients with clinically suspected ILD with normal or equivocal radiographs.

\section{Exclusion Criteria}

1. Known cases of infective aetiology (Tuberculosis, HIV).

2. Known cases of chronic obstructive pulmonary disease.

3. Known cases of congestive cardiac failure.

4. Known cases of lung malignancy.

5. Hemodynamically unstable patients.

6. Pregnant patients.

7. Age $<15$ years.

After inclusion of the patient in the study, detailed proforma was filled. The proforma included the patient's name, age, address, medical record number, complaints, risk factors, past history, laboratory investigation, and chest radiograph findings.

Thereafter HRCT chest was done using GE 16 SLICE BRIGHTSPEED SCANNER in supine position using standard HRCT protocol. Prone and expiratory scanning was done wherever needed.

\section{Statistical Analysis}

Statistical analysis was performed by using the Chi- square test and EPI. Info 7.2 program for windows. It is a nonparametric data therefore Chi- square test was applied for taking inferences. A p- value of less than 0.05 was considered statistically significant.

\section{RESULTS}

Of the 40 patients, 26 patients were males (65\%) and 14 (35\%) were females. The age of the patients ranged from 30 years to 74 years.
The most common presenting clinical feature was dyspnoea on exertion present in $65 \%$ of patients followed by the cough which was present in $56 \%$ of cases. Fever was present in $28 \%$ patients while arthralgia was seen in $10 \%$ of patients. And weight loss was seen in $8 \%$ of patients.

The spectrum of diseases included in the study was:

Idiopathic pulmonary fibrosis (25\%), hypersensitivity pneumonitis (17.5\%), Sarcoidosis (15\%), rheumatoid arthritis (10\%), silicosis (10\%), LAM (7.5\%), allergic bronchopulmonary aspergillosis (5\%) and lymphangitis carcinomatosis (5\%), COP (5\%). The comparison between Xray and HRCT in the detection of different findings are given below.

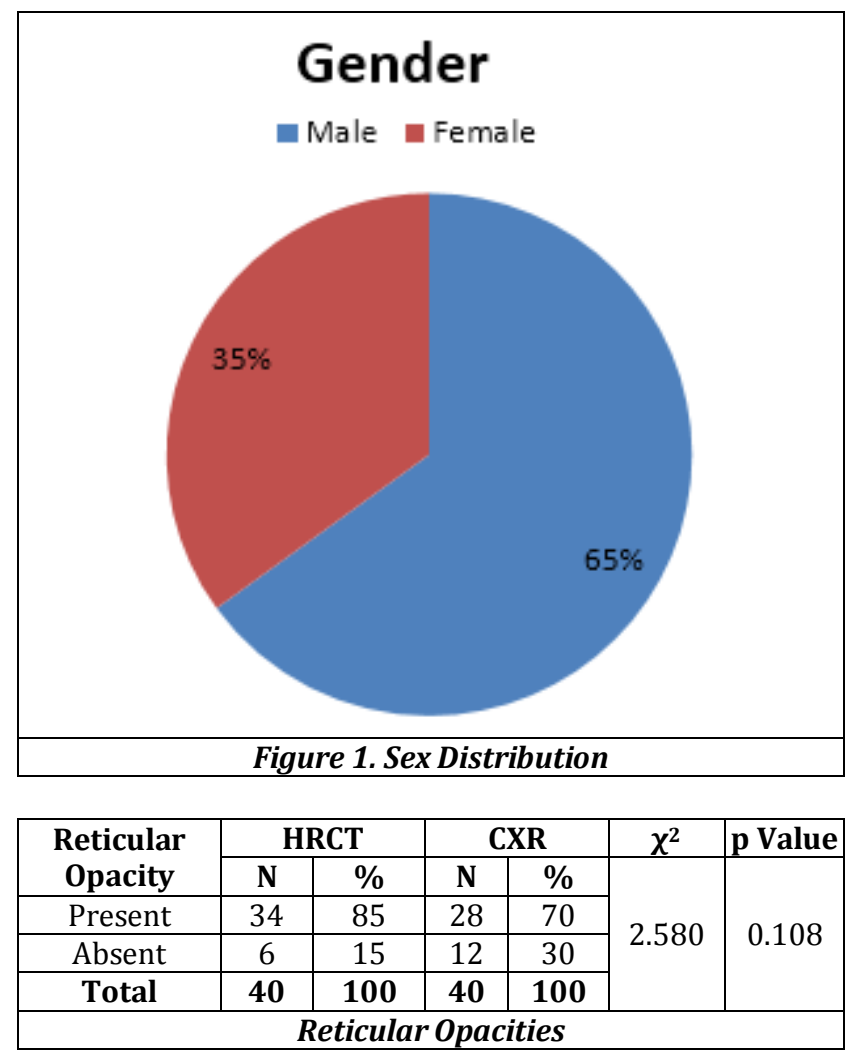

Higher number of reticular opacity were detected on HRCT thorax as compared to chest X-ray but it was not statistically significant $(\mathrm{P}>0.05)$.

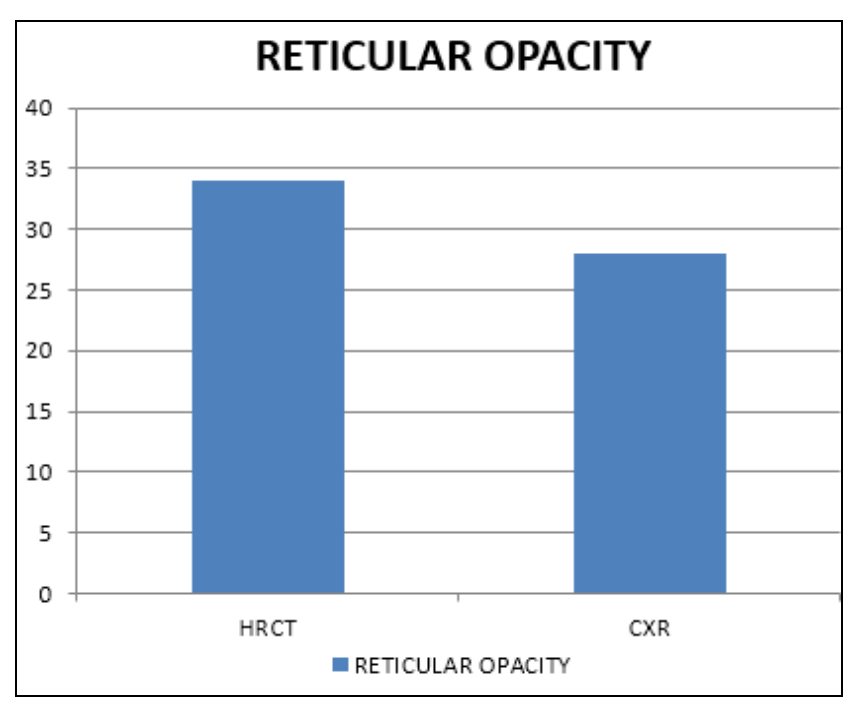




\begin{tabular}{|c|c|c|c|c|c|c|}
\hline \multirow{2}{*}{$\begin{array}{c}\text { Nodular } \\
\text { Opacity }\end{array}$} & \multicolumn{2}{|c|}{ HRCT } & \multicolumn{2}{|c|}{ CXR } & \multirow{2}{*}{$\chi^{\mathbf{2}}$} & $\begin{array}{c}\text { p } \\
\text { Value }\end{array}$ \\
\cline { 2 - 5 } & $\mathbf{N}$ & $\mathbf{\%}$ & $\mathbf{N}$ & $\mathbf{\%}$ & & \\
\hline Present & 27 & 67.5 & 14 & $35 \%$ & \multirow{2}{*}{8.455} & 0.003 \\
\hline Absent & 13 & 32.5 & 26 & $65 \%$ & & \\
\hline Total & $\mathbf{4 0}$ & $\mathbf{1 0 0}$ & $\mathbf{4 0}$ & $\mathbf{1 0 0}$ & & \\
\hline \multicolumn{7}{|c|}{ Nodular Opacity } \\
\hline
\end{tabular}

Higher number of nodular opacities were detected on HRCT thorax as compared to chest X-ray and it was statistically significant $(\mathrm{P}<0.05)$.

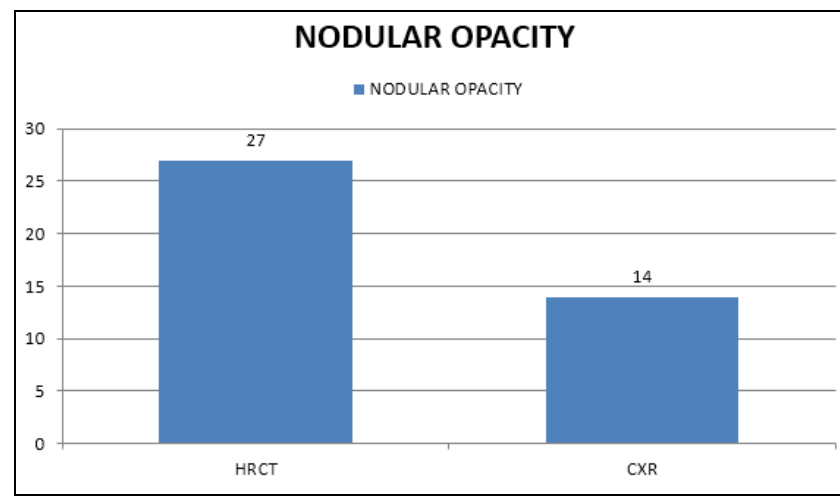

\begin{tabular}{|c|c|c|c|c|c|c|}
\hline \multirow{2}{*}{$\begin{array}{c}\text { Septal } \\
\text { Thickening }\end{array}$} & \multicolumn{2}{|c|}{ HRCT } & \multicolumn{2}{|c|}{ CXR } & \multirow{2}{*}{$\chi^{2}$} & $\begin{array}{c}\text { p } \\
\text { Value }\end{array}$ \\
\cline { 2 - 6 } & $\mathbf{N}$ & $\mathbf{\%}$ & $\mathbf{N}$ & $\mathbf{\%}$ & & \\
\hline Present & 28 & 70 & 16 & 40 & \multirow{2}{*}{7.272} & 0.007 \\
\hline Absent & 12 & 30 & 24 & 60 & & \\
\hline Total & $\mathbf{4 0}$ & $\mathbf{1 0 0}$ & $\mathbf{4 0}$ & $\mathbf{4 0}$ & & \\
\hline \multicolumn{7}{|c|}{ Septal Thickening } \\
\hline
\end{tabular}

Higher number of septal thickening were detected on HRCT thorax as compared to chest X-ray and it was statistically significant $(\mathrm{P}<0.05)$.

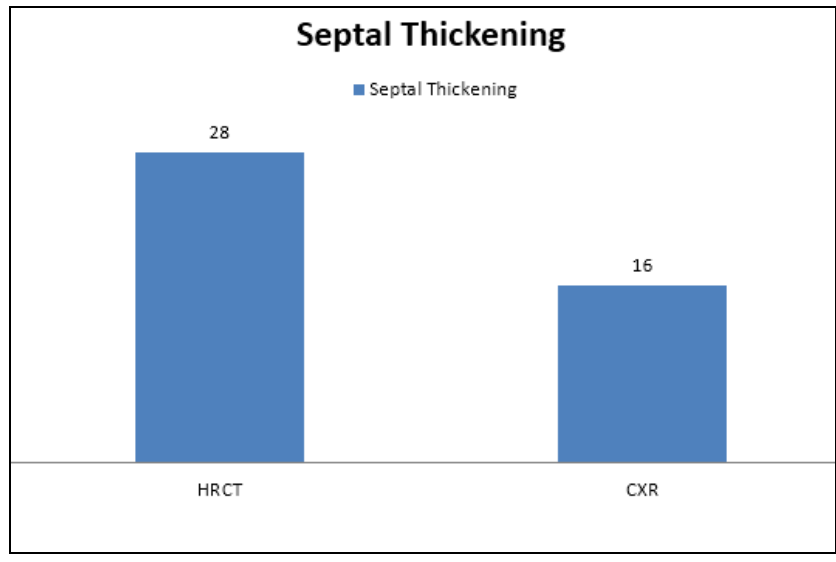

\begin{tabular}{|c|c|c|c|c|c|c|}
\hline \multirow{2}{*}{$\begin{array}{c}\text { Honey } \\
\text { combing }\end{array}$} & \multicolumn{2}{|c|}{ HRCT } & \multicolumn{2}{|c|}{ CXR } & $\chi^{2}$ & p Value \\
\cline { 2 - 5 } & $\mathbf{n}$ & $\mathbf{\%}$ & $\mathbf{N}$ & $\mathbf{\%}$ & & \\
\hline Present & 14 & 35 & 7 & 17.5 & \multirow{3}{*}{3.163} & 0.075 \\
\hline Absent & 26 & 65 & 33 & 82.5 & & \\
\hline Total & $\mathbf{4 0}$ & $\mathbf{1 0 0}$ & $\mathbf{4 0}$ & $\mathbf{1 0 0}$ & & \\
\hline \multicolumn{7}{|c|}{ Honeycombing } \\
\hline
\end{tabular}

Higher number of honeycombing were detected on HRCT thorax as compared to chest X-ray but it was not statistically significant $(\mathrm{P}>0.05)$.

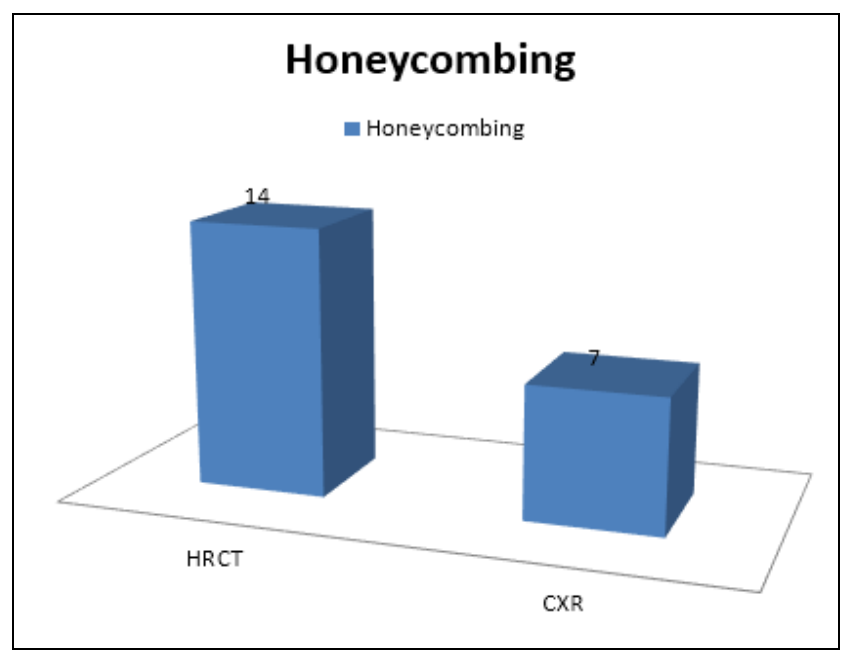

\begin{tabular}{|c|c|c|c|c|c|c|}
\hline Traction & \multicolumn{2}{|}{ HRCT } & \multicolumn{2}{|c|}{ CXR } & \multirow{2}{*}{$\boldsymbol{\chi}^{\mathbf{2}}$} & p Value \\
\cline { 2 - 5 } Bronchiectasis & $\mathbf{N}$ & $\mathbf{\%}$ & $\mathbf{N}$ & $\mathbf{\%}$ & & \\
\hline Present & 18 & 45 & 12 & 30 & \multirow{2}{*}{1.92} & \multirow{2}{*}{0.165} \\
\hline Absent & 22 & 55 & 28 & 70 & & \\
\hline Total & $\mathbf{4 0}$ & $\mathbf{1 0 0}$ & $\mathbf{4 0}$ & $\mathbf{1 0 0}$ & & \\
\hline \multicolumn{7}{|c|}{ Traction Bronchiectasis } \\
\hline
\end{tabular}

Higher number of traction bronchiectasis were detected on HRCT thorax method as compared to chest X-ray but it was not statistically significant $(\mathrm{P}>0.05)$.

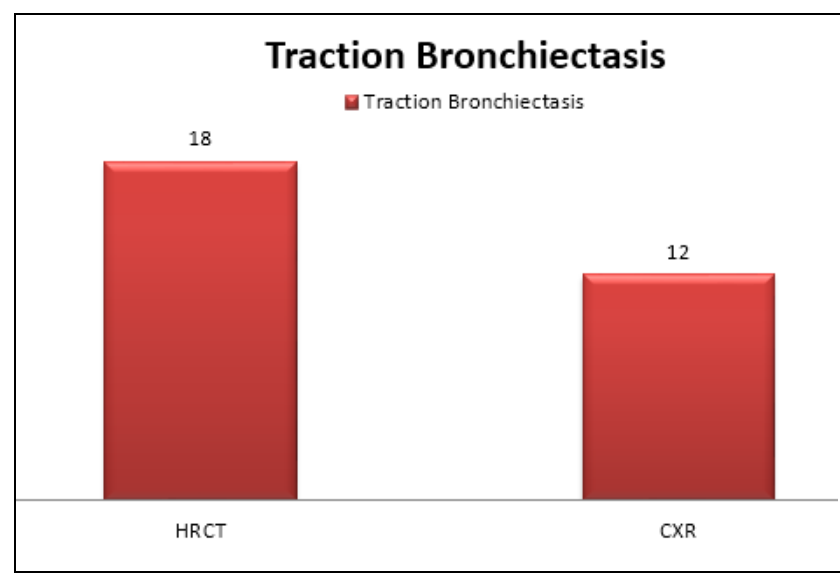

\begin{tabular}{|c|c|c|c|c|c|c|}
\hline \multirow{2}{*}{ Consolidation } & \multicolumn{2}{|c|}{ HRCT } & \multicolumn{2}{|c|}{ CXR } & \multirow{2}{*}{$\boldsymbol{\chi}^{2}$} & p Value \\
\cline { 2 - 5 } & $\mathbf{N}$ & $\mathbf{\%}$ & $\mathbf{N}$ & $\mathbf{\%}$ & & \multirow{3}{*}{1.289} \\
\hline Present & 19 & 47.5 & 14 & 35 & 0.256 \\
\hline Absent & 21 & 52.5 & 26 & 65 & & \\
\hline Total & $\mathbf{4 0}$ & $\mathbf{1 0 0}$ & $\mathbf{4 0}$ & $\mathbf{1 0 0}$ & & \\
\hline \multicolumn{7}{|c|}{ Consolidation } \\
\hline
\end{tabular}

HRCT thorax detected higher number of consolidation than chest X-ray but it was not statistically significant $(\mathrm{P}>0.05)$. 


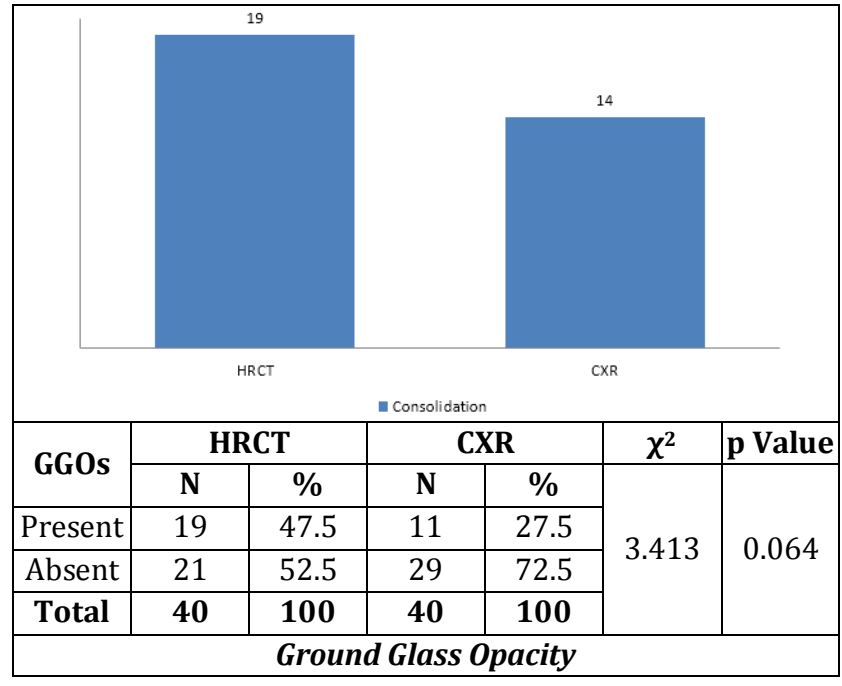

HRCT thorax detected higher no. of ground glass opacity than chest X-ray but it was not statistically significant $(\mathrm{P}>0.05)$.

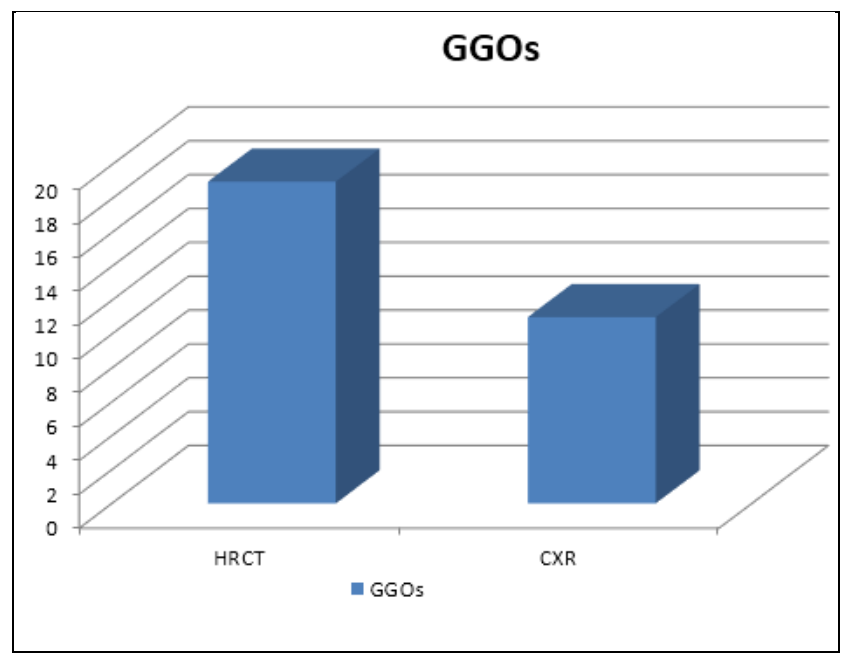

\begin{tabular}{|c|c|c|c|c|c|c|}
\hline \multirow{2}{*}{$\begin{array}{c}\text { Lymph- } \\
\text { adenopathy }\end{array}$} & \multicolumn{2}{|c|}{ HRCT } & \multicolumn{2}{|c|}{ CXR } & \multirow{2}{*}{$\chi^{\mathbf{2}}$} & $\begin{array}{c}\mathbf{p} \\
\text { Value }\end{array}$ \\
\cline { 2 - 5 } & $\mathbf{N}$ & $\mathbf{\%}$ & $\mathbf{N}$ & $\mathbf{\%}$ & & \\
\hline Present & 27 & 67.5 & 10 & 25 & \multirow{2}{*}{14.531} & 0.0001 \\
\hline Absent & 13 & 32.5 & 30 & 75 & & \\
\hline Total & $\mathbf{4 0}$ & $\mathbf{1 0 0}$ & $\mathbf{4 0}$ & $\mathbf{1 0 0}$ & & \\
\hline \multicolumn{7}{|c|}{ Lymphadenopathy } \\
\hline
\end{tabular}

HRCT thorax detected higher number of lymphadenopathy than chest X-ray and it was statistically significant $(\mathrm{P}<0.05)$.

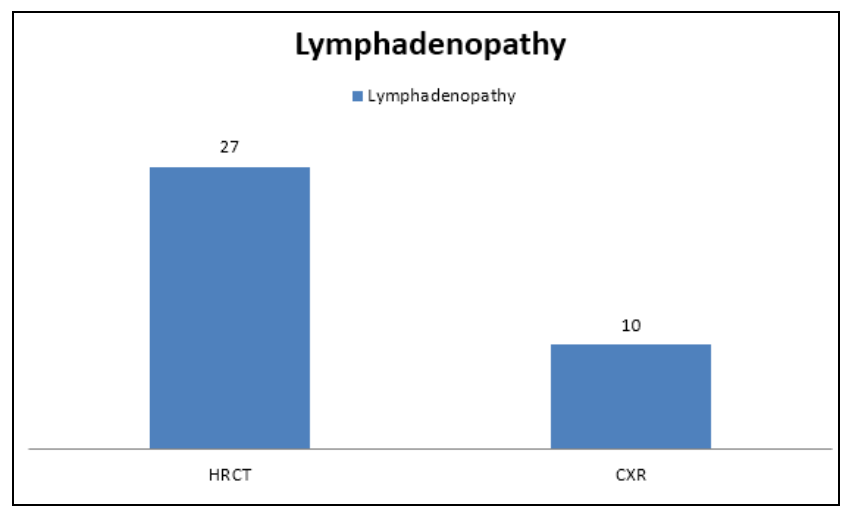

\section{DISCUSSION}

The main observation in our study was that higher numbers of samples with findings were detected by HRCT as compared to conventional radiography. Even when both modalities were able to detect the findings, HRCT could characterize the abnormality and specify its location much more accurately. The chest radiogram can appear completely normal in patients suffering from interstitial lung diseases. Therein lays the inherent lack of sensitivity of conventional chest radiography in the diagnosis of the conditions. In our study, 6 of the 40 patients $(6.7 \%)$ had no abnormalities in their chest radiographs. However HRCT was able to show reticular changes in these patients.

\section{CONCLUSION}

The diagnosis of interstitial lung disease (ILD) is most of the times delayed because clinical findings are neglected and respiratory symptoms are thought to be of more common pulmonary diagnoses such as chronic obstructive pulmonary disease (COPD) in the primary care setting. In patients with progressive dyspnoea ILD should be ruled out as this is the most common complaint in ILD patients.

HRCT is able to detect abnormalities in patients when the clinical signs are very few or even when the chest radiograph appears completely normal. Chest radiography is a relatively insensitive modality of investigation for the diagnosis of ILDs. Ultimately all patients with clinical suspicion of ILDs should benefit from an HRCT scan of the thorax. High resolution computed tomography (HRCT) chest scans are very essential to the diagnostic work-up since each ILD form is characterized by a specific pattern of abnormalities and a confident diagnosis can often be arrived at by HRCT alone or in correlation with the clinical symptoms. When HRCT findings are characteristic in appropriate clinical settings, HRCT may even obviate the need for a lung biopsy.

\section{REFERENCES}

[1] Behr J, Ryu JH. Pulmonary hypertension in interstitial lung disease. Eur Respir J 2008;31(6):1357-67.

[2] American Thoracic Society. Idiopathic pulmonary fibrosis: diagnosis and treatment. International consensus statement. American Thoracic Society (ATS) and the European Respiratory Society (ERS). Am J Respir Crit Care Med 2000;161(2 Pt 1):646-64.

[3] Ryu JH, Daniels CE, Hartman TE, et al. Diagnosis of interstitial lung diseases. Mayo Clin Proc 2007;82(8):976-86.

[4] Ward J, McDonald C. Interstitial lung disease: an approach to diagnosis and management. Australian Family Physician 2010;39(3):106-10.

[5] MacMahon H, Austin JH, Gamsu G, et al. Guidelines for management of small pulmonary nodules detected on CT scans: a statement from the Fleischner Society. Radiology 2005;237(2):395-400.

[6] Strange C, Highland KB. Interstitial lung disease in the patient who has connective tissue disease. Clinics in Chest Medicine 2004;25(3):549-59, vii.

[7] Sharma RP, Kaur G, Arora A, et al. Interstitial lung disease in rheumatoid arthritis: a study of thirty cases. Chest 2006;16:835-9. 


\section{Jemds.com}

[8] Raghu G, Brown KK. Interstitial lung disease: clinical evaluation and keys to an accurate diagnosis. Clin Chest Med 2004;25(3):409-19, v.
Original Research Article

[9] Lynch D. Imaging of diffuse parenchymal lung disease. In: Schwarz MI, King TE, eds. Interstitial lung disease. $4^{\text {th }}$ edn. Hamilton (Ontario): BC Decker Inc., 2003. 